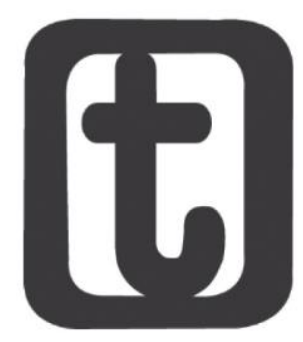

\title{
ENVELHECIMENTO E VELHICE: PROTAGONISMO, TEMPORALIDADE E DESAFIOS1
}

\author{
Aging and old age: protagonism, temporality and challenges
}

\author{
Karine Kátia Iria Luiz* \\ Maria das Dôres Saraiva de Loreto** \\ Simone Caldas Tavares Mafra*** \\ Marco Aurélio Marques Ferreira****
}

RESUMO

Buscou-se compreender o significado do envelhecimento e da velhice para idosos que participam do Conselho Municipal do idoso, em cidades da região da Zona da Mata mineira. Realizou-se uma pesquisa qualitativa, descritiva e exploratória, utilizando-se da entrevista aberta, analisadas com o auxílio do software livre Iramuteq. O significado de envelhecimento e velhice, de acordo com a Nuvem de Palavras e a análise de conteúdo remeteram-se, principalmente, às palavras "vida" e "saúde", indicando que o envelhecer é um processo natural da vida humana, que pode ser ativo, tendo saúde. Agradecem a Deus, pelos desafios superados, pela família e pela casa, como lugar seguro. Como forma de aprofundar nesse significado, foi realizada a Análise Hierárquica Descendente, cujas classes resultantes destacam uma etapa ativa (protagonismo) em contraposição a uma fase de limitações (desafios). Pode-se concluir que o significado do envelhecimento e da velhice para os idosos entrevistados tem relação direta com o seu contexto de vida e

\footnotetext{
${ }^{1}$ Este artigo apresenta os resultados parciais de uma tese de doutorado, em andamento.

* Economista doméstico. Mestre em Economia Doméstica (UFV). Doutoranda em Economia Doméstica no programa de Pós-graduação em Economia Doméstica da Universidade Federal de Viçosa, UFV, Viçosa-MG, Brasil. E-mail: <karine.iria@gmail.com >. ORCID: https://orcid.org/0000-0002-6380-6664.

**Economista Doméstico. Doutorado em Economia Aplicada. Pós-Doutorado em Família e Meio Ambiente pela University of Guelph - Canadá. Professora Titular da Universidade Federal de Viçosa, Departamento de Economia Doméstica, UFV, Viçosa-MG, Brasil. E-mail: <mdora@ufv.br > ORC ID: https://orcid.org/0000-0001-7418-2669.

*** Economista Doméstico. Doutorado em Engenharia de Produção. Pós-Doutorado em Minority Aging pela University of Texas Medical Branch, Texas, EUA. Professora Titular da Universidade Federal de Viçosa, Departamento de Economia Doméstica, UFV, Viçosa-MG, Brasil. E-mail: <sctmafra@ufv.br>. ORC ID: https://orcid.org/0000-0003-2247-2327.

**** Administrador. Pós-Doutorado em Administração Pública por Rutgers University - The State University of New Jersey, USA. Professor Associado da Universidade Federal de Viçosa, Departamento de Administração e Contabilidade, UFV, Viçosa-MG, Brasil. E-mail: <marcoufv1@gmail.com>. ORCID: https://orcid.org/oooo0002-9538-1699.
} 
experiências, destacando-se por aspectos ligados ao protagonismo, à temporalidade e aos desafios do dia-a-dia.

PALAVRAS-CHAVE: Representação Social. Envelhecimento. Velhice.

ABSTRACT: The objective was to understand the meaning of aging and old age for elderly people who participate in the Municipal Council of the elderly, in cities in the region of Zona da Mata, Minas Gerais. A qualitative, descriptive and exploratory research was carried out, using the open interview, analyzed with the help of free software Iramuteq. The meaning of aging and old age, according to the Word Cloud and content analysis, were mainly related to the words "life" and "health", indicating that aging is a natural process of human life, which can be active, having health. They thank God, for the challenges overcome, for the family and for the house, as a safe place. As a way of deepening this meaning, the Descending Hierarchical Analysis was carried out, whose resulting classes highlight an active stage (protagonism) as opposed to a phase of limitations (challenges). It can be concluded that the meaning of aging and old age for the elderly interviewed is directly related to their life context and experiences, emphasizing aspects related to protagonism, temporality and the challenges of everyday life.

KEYWORDS: Social representation. Aging. Old age.

Submetido em: 21/11/2017.

Aceito em: 28/5/2018.

\section{INTRODUÇÃO}

O envelhecimento populacional é uma realidade no contexto brasileiro, que segue uma tendência mundial, ocasionada pela redução da taxa natalidade e mortalidade, bem como ao aumento da longevidade. Associa-se a isso, o avanço da medicina, a melhoria do saneamento básico e das condições de vida, com repercussões na qualidade de vida (BRITO, 2007, OLIVEIRA; GUIMARÃES; RODRIGUES JÚNIOR, 2015, CARVALHO; ALVES, 2012, PESSIN; ISTOE; MANHÃES, 2015, FERNANDES et al., 2015). Estimativas populacionais, de acordo com Alves (2014), apontam que, em 2030, o número de idosos irá se igualar ao de crianças e jovens e, em 2055, haverá 208 idosos para cada 100 pessoas de 0 a 14 anos. Fernandes et al (2015) ressaltam que, com o cálculo populacional de cerca de 58,4 milhões de idosos em 2060, há interesse e preocupação em compreender o envelhecimento e seus possíveis impactos na sociedade.

Neste contexto, é importante ressaltar que o aumento da longevidade, além de alterar a configuração da pirâmide etária, traz implicações também para as relações sociais (PESSIN; ISTOE; MANHÃES, 2015). Igualmente, Oliveira, Guimarães e Rodrigues Júnior (2015) afirmam que o envelhecimento humano suscita inquietações no que diz respeito às repercussões sociais e de adaptabilidade dos indivíduos, devido à presença de alguns fatores e eventos que interferem diretamente no bem-estar físico e social desses sujeitos.

Concernente ao envelhecimento, pode-se dizer, conforme Figueiredo et al (2011), que se trata de um processo multidimensional, centrado na interdependência entre as dimensões biológicas (mudanças no corpo), psicológicas (cognição, personalidade e afetividade) e sociais (refletem o domínio sociocultural e ambiental, que revelam indicadores de saúde familiar e social). Por se tratar de um assunto tão emergente e com implicações

Temporalis, Brasília (DF), ano 18, n. 35, jan./jun. 2018. 
significativas para toda a sociedade, faz-se necessário, de acordo com Amaral, Guimarães e Lima (2015), repensar as políticas públicas destinadas ao envelhecimento e a maneira como são administradas pelo Estado e sociedade. Peixoto (2004) lembra que, diante da diversidade de estudos realizados ao longo do século $\mathrm{XX}$, encontram-se aqueles que elegeram as políticas sociais da velhice como pontos principais de reflexão, com o propósito de minimizar a pobreza das pessoas envelhecidas. Silva (2006) ressalta sobre esse fato, uma vez que, no mundo contemporâneo, a velhice tornou-se uma questão social e política, contrapondo a realidade que se manteve até o final da primeira metade do século XIX, em que esse assunto estava restrito à esfera privada e familiar.

Em se tratando de uma questão social e política, Silva e Carmo (2015) declararam que, no Brasil, no âmbito legal, os idosos foram referenciados, pela primeira vez, na Constituição de 1988. Nesse momento, recebeu uma atenção especial e a velhice começou a ser tratada como direito humano fundamental. A partir dela, abriu-se um vasto conjunto de leis, especialmente voltadas para a população idosa, que passou a ser catalogada como um público específico e com características biológicas, psicológicas e sociais próprias, demandando leis, políticas e tratamentos exclusivos, revelando a intenção do Estado em regular o envelhecimento populacional (ROZENDO, 2010).

Para o referido autor, essa intenção de regular o envelhecimento, com leis e normas, acaba por extrapolar o campo de garantias de direitos e políticas públicas, influenciando, também, na forma como a sociedade age e pensa sobre o envelhecimento e a velhice, pois traz consigo um conjunto de simbologias, imagens, ideais e valores que orientam as imagens, concepções, representações e afetos dirigidos aos mais velhos. No entanto, mais do que compreender essa realidade, faz-se necessário que os idosos, como os sujeitos mais interessados em ter maior visibilidade e legitimidade, sejam incluídos em todos os seguimentos da sociedade, afim de que possam contribuir para o desenvolvimento da mesma (AMARAL; GUIMARÃES; LIMA, 2015). Isso implica, de acordo com Coelho (2009), em uma vivência plena de sua cidadania, não expressa somente na posse de uma certidão de nascimento ou um título de eleitor, mas uma cidadania concreta e real, que se efetiva dentro de cada pessoa.

Perante as implicações trazidas pelo envelhecimento populacional e sua representação social, buscou-se compreender o significado do envelhecimento e da velhice para idosos que participam do Conselho Municipal do idoso. Tal estudo parte do princípio que esses idosos exercem sua cidadania e também são formadores de opinião, uma vez que representam seus pares e buscam contribuir para maior conhecimento de seus direitos e deveres.

\section{REVISÃO DE LITERATURA}

A maneira como o envelhecimento e a velhice são compreendidos pelos sujeitos está intimamente ligada ao contexto socioeconômico e cultural onde se está inserido, às informações que circulam acerca dessa realidade, às condições de saúde, além das redes de relações que se estabelece, tanto na família quanto nos diversos ambientes de convivência, incluindo o virtual; perpassa, também, o contexto político e a construção de práticas sociais cidadãs de modo que os idosos vivam plenamente seus direitos e deveres.

Temporalis, Brasília (DF), ano 18, n. 35, jan./jun. 2018. 
O respeito aos direitos dos idosos, de acordo com Gomes e Istoe (2015), depende da compreensão das pessoas sobre o envelhecimento, como processo contínuo e permanente ao longo da vida. Os autores chamam a atenção para o fato de que o tratamento conferido aos idosos nem sempre demonstra investimento na dissolução de preconceitos e discriminações e que isso ocorre quando o idoso não tem conhecimento sobre o conjunto de ações voltadas para sua proteção e valorização. Neste sentido, o exercício da cidadania, entendida como luta para se conquistar algo, na visão de Coelho (2009), apesar de mais exaustiva, possibilita construção e mudança da própria história, além de colaborar com a história de outras pessoas, tornando-se, ele próprio, um patrimônio humano, produzido e colocado à disposição da coletividade. Nesta direção, Osterne (2008) fala sobre um novo paradigma de cidadania, que se constitui de sujeitos sociais ativos, capazes de estabelecer o que consideram ser os seus direitos e lutam pelo seu reconhecimento.

De acordo com Rozendo (2010), na sociedade, existem formas de organização que possibilitam o exercício da cidadania e são denominados Conselhos. Na visão do referido autor, a criação dos Conselhos do Idoso, nas esferas nacional, estadual e municipal, foi o principal destaque da Política Nacional do Idoso. Eles foram estabelecidos como órgãos permanentes e deliberativos, e têm a responsabilidade de formular, coordenar, supervisionar e avaliar as políticas do idoso. Bredemeier (2002) ressalta que:

\begin{abstract}
Os conselhos são formados por um número de representantes do poder público igual ao número de representantes da sociedade civil que engloba tanto os prestadores de serviços, os técnicos ou administradores, como grupos de idosos onde o idoso faz sua representação. Isto confere aos conselhos do idoso uma característica própria, uma vez que o próprio idoso, alvo das ações e políticas em questão, compõe o corpo de conselheiros, diferentemente dos conselhos da criança e do adolescente, conselhos da saúde ou da assistência onde, poucas vezes, o usuário dos serviços tem ocupado o assento que tem por direito. É importante frisar que se considera esta possibilidade um avanço, pois abre novas perspectivas para a participação e para a autonomia do idoso (BREDEMEIER, 2002, p. 2).
\end{abstract}

A autonomia, de acordo com Fonseca e Siqueira (2015), representa atitudes e comportamentos que se aceira de livre escolha e é um fator preponderante para a qualidade de vida, durante o processo de envelhecimento. Processo este que, na visão de Gomes e Istoe (2015), deve ser abordado levando-se em conta a multiplicidade de interpretações a seu respeito, pois não se refere somente a um processo fisiológico, mas também ao percurso social e histórico vivenciado. Para essas autoras, os dados relativos aos discursos e relações de poder, que constituem a velhice, devem ser contemplados, pois formam suas identidades, modos de gestão de si e da vida. Para tanto, faz-se necessário desnaturalizar o processo de envelhecimento, pois ele vai além de uma materialidade situada na natureza, se expandindo numa materialidade simbólica, tecida nas relações sociais. Isso se evidencia na produção de significação das práticas pelas quais a velhice é figurada, compreendida e fincada no imaginário social (ROZENDO, 2010).

A compreensão dos fenômenos sociais é elaborada coletivamente, na forma de representações sociais. A Teoria das Representações Sociais, desenvolvida por Serge

Temporalis, Brasília (DF), ano 18, n. 35, jan./jun. 2018. 


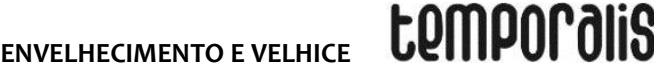

Moscovici, evidencia-se por sua pluralidade metodológica, temática e conceitual, interessando os domínios da psicologia social, sociologia e antropologia. Mostra-se, então, como a sua concepção é complexa, tendo em vista a multidimensionalidade em que se constitui (SILVA, 2006).

Para Camargo et al. (2014), uma representação social é tridimensional, pois envolve a dimensão informacional, atitudinal (ou avaliativa) e figurativa, que se constitui como produto do processo de objetivação. Silva (2006) destaca que o mecanismo da objetivação, que permite a edificação de um saber comum, em que se pode emitir opiniões e mudanças, se completa com a ancoragem, que consiste no enraizamento dessa representação, passando a ser usada cotidianamente, nas relações sociais. Essa ancoragem pode transformar as representações sociais já constituídas ou ser um instrumento estabilizador e redutor de novas aprendizagens.

A partir dessa compreensão, Gomes e Istoe (2015) consideram de extrema necessidade pensar sobre as representações sociais do idoso e do envelhecimento humano, de modo geral, compreendidas em sua especificidade e complexidade. Afinal, conforme salientam Guerra e Caldas (2010), não é correto e nem se pode generalizar as imagens e representações dos idosos a respeito do próprio envelhecimento, para toda uma população, sendo necessário investigar cada população, considerando a situação socioeconômica, a cultura, a religião, as atividades, as regionalidades e, principalmente, a individualidade de cada idoso. Além disso, as interações e os laços sociais que se estruturam na contemporaneidade também precisam ser considerados nas representações sociais sobre envelhecimento e velhice, pois, como destacam Souza, Boechat e Cabral (2015), com o uso crescente das mídias digitais, tem-se a configuração de redes sociais digitais, cada vez mais presente do cotidiano dos idosos, possibilitando outras interações.

Outro aspecto a ser considerado diz respeito ao estereótipo e estigma vivenciados pelos idosos, bem como os preconceitos que se objetivam e ancoram na sociedade, constituindo o imaginário social sobre o significado do envelhecimento e velhice. Para Barros (2004), trata-se de estudar a relação entre as particularidades das experiências socioculturais e a universalidade da vida em sociedade, ameaçada pelos estigmas caracterizadores da velhice. Como exemplo, essa autora cita que a noção de terceira idade, acompanhada de ideais de sociabilidade, que assegurariam a boa inserção do indivíduo velho na sociedade, são barrados por valores construídos pela própria sociedade: a intolerância diante daqueles que não conseguem acompanhar os padrões ideais de comportamento, aparência e produtividade. Além disso, há uma progressiva responsabilização dos idosos por seu próprio bem-estar, de modo que, se a velhice não é bem-sucedida, isso ocorre por incapacidade do próprio indivíduo.

No entanto, embora a autonomia e a independência possam facilitar que os idosos sejam protagonistas de sua velhice, fatores ligados a saúde, relações sociais, familiares e econômicas, que estão além de seu controle, também influenciam seu bem-estar. Sobre essa questão, Doll (2006) considera que, na discussão sobre mitos e verdades sobre bemestar na velhice, o que importa, de fato, é a perspectiva das próprias pessoas idosas, buscando compreender o sentido que dão à vida, sua espiritualidade, desafiando um

Temporalis, Brasília (DF), ano 18, n. 35, jan./jun. 2018. 
discurso impositivo sobre o que é bom ou ruim, proposto muitas vezes no discurso gerontológico.

\section{METODOLOGIA}

Realizou-se uma pesquisa qualitativa, descritiva e exploratória, utilizando-se da entrevista aberta como técnica de coleta de dados. Os entrevistados, além de responderem, livremente a pergunta $O$ que significa para o(a) senhor(a) o envelhecimento e a velhice, também responderam um questionário contendo informações a respeito de seu perfil socioeconômico, estrutura familiar, condições de saúde, religião, participação em grupos e redes sociais.

Os dados foram coletados entre março e agosto de 2017, nas cidades de Ubá, Juiz de Fora, Ponte Nova, Visconde do Rio Branco e Viçosa. Realizou-se oito entrevistas no total, gravadas em áudio, com idosos que participam do Conselho Municipal do Idoso. O estudo foi aprovado pelo Comitê de Ética em Pesquisa com Seres Humanos (CEP), da Universidade Federal de Viçosa, projeto de pesquisa $\mathrm{n}^{\circ}$ 1.956.271, e os participantes assinaram um Termo de Consentimento Livre e Esclarecido antes de sua inclusão na pesquisa.

Após a transcrição das entrevistas, a análise dos dados contou com o auxílio do software livre Iramuteq, que permite uma análise lexical, considerando a palavra como unidade e possibilitando contextualizá-la em seu corpus. Optou-se por realizar a análise da Nuvem de Palavras, acompanhada de uma análise de conteúdo e, posteriormente, obteve-se a Classificação Hierárquica Descendente (CHD). A Nuvem de Palavras permite visualizar, imediatamente, as palavras estruturadas em forma de nuvens, com tamanhos diferentes, conforme a frequência das palavras e sua relevância (LINS, [2017]). A CHD, por sua vez, agrupa os segmentos dos textos e vocabulários correlacionando-os por conteúdo, em um esquema hierárquico de classes, que representam o espaço de sentido das palavras, sugerindo elemento pertencentes às representações sociais (SILVA; BOUSFIELD; CARDOSO, 2013).

\section{RESULTADOS E DISCUSSÕES}

\section{Perfil dos idosos entrevistados}

A partir dos dados do questionário, identificou-se que, dos oito entrevistados, três eram homens e cinco mulheres, com a idade variando entre 62 e 82 anos. Quanto ao estado civil, quatro eram casados (dois homens e duas mulheres) e um declarou união estável; duas mulheres declararam que são separadas e uma, viúva. Metade dos entrevistados têm curso superior, outros três estudaram o equivalente ao ensino fundamental incompleto ( $4^{a}$ série) e apenas um declarou ter o ensino fundamental completo. Nenhum deles mora sozinho, todos são aposentados e seis afirmaram ter outra ocupação; sendo que a renda familiar declarada variou entre 1 e 18 salários mínimos. No que diz respeito à saúde, apenas duas mulheres (uma com 74 e outra com 69 anos) afirmaram não ter nenhum problema de saúde e, portanto, sem necessidade de medicamento de uso contínuo. Diante da pergunta sobre necessidade de auxílio para atividades diárias, somente um afirmou necessitar de ajuda quando a atividade envolvia carregar peso.

Temporalis, Brasília (DF), ano 18, n. 35, jan./jun. 2018. 
Sobre a religião, seis dos participantes se declararam católicos, uma espiritualista e outra cristã; sendo que todos participam de alguma atividade em grupo e, no que diz respeito ao uso de redes sociais, a maioria respondeu afirmativamente. Quando perguntados sobre como acham que são percebidos por jovens, a maioria afirmou que se sente valorizado, como alguém que tem muito conhecimento e merece respeito.

\section{Significado do Envelhecimento e Velhice: Nuvem de Palavras e Análise de Conteúdo}

Para análise do significado das palavras envelhecimento e velhice, dadas pelos entrevistados, utilizou-se, primeiramente, do recurso conhecido como Nuvem de Palavras, apresentada na Figura 1, tendo sido mais evocadas as seguintes palavras: vida, casa, Deus, família e saúde. Como a palavra vida se destacou mais que todas a outras, buscou-se identificar o seu contexto nas entrevistas e observou-se que os idosos se remeteram a ela em três circunstâncias distintas e, ao mesmo tempo, interligadas. Eles indicam como a vida dever ser (saudável e com atividade); mostram-se contentes com ela (maravilhosa, vitória, feliz); e ainda afirmam que a vida não acaba na velhice e devem dar continuidade a ela (dando seguimento, tocando, levando e vivendo).

Figura 1: Nuvem de Palavras representativas da percepção do envelhecimento e velhice.

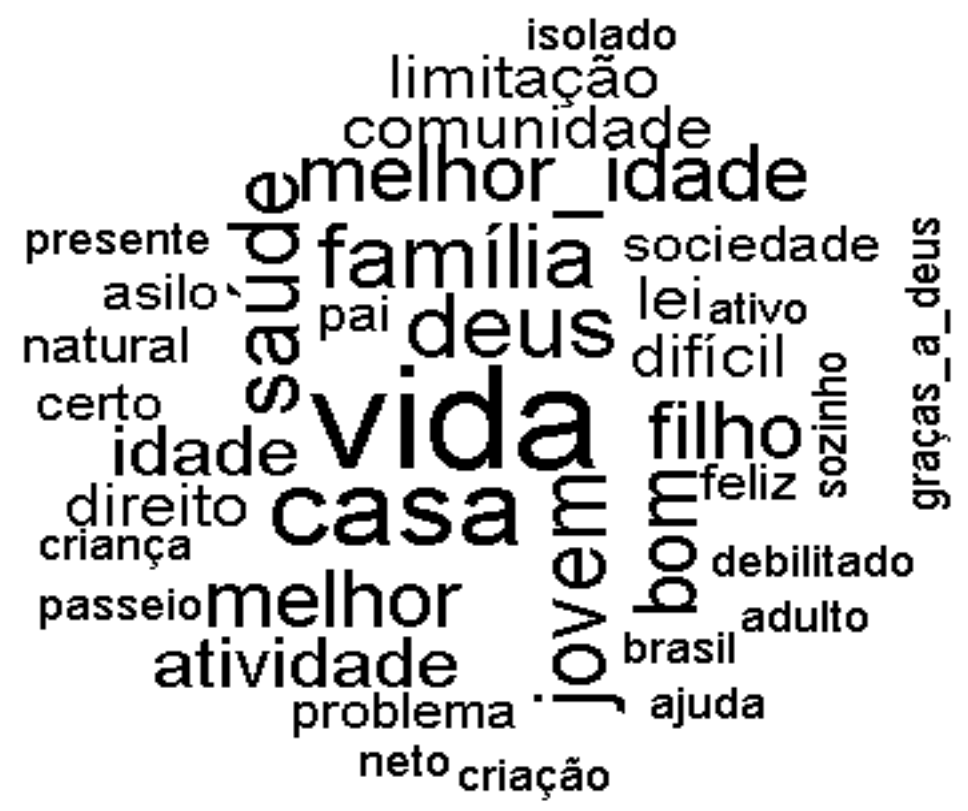

Fonte: Dados da pesquisa.

Em um segundo momento, buscou-se, também, identificar as palavras que mais se repetiram nas respostas, por meio de análise de conteúdo. Verificou-se que as palavras relacionadas a processo natural da vida (87,5\%), saúde ( $87,5 \%)$, família $(62,5 \%)$, casa (50\%) e gratidão (50\%) foram as que mais se destacaram nos discursos dos entrevistados, confirmando-se a Nuvem de Palavras que foi gerada anteriormente e ajudando a entendêla melhor. 
De um modo geral, pode-se dizer que, para eles, o envelhecimento é um acontecimento natural, que faz parte da vida. A velhice, por sua vez, também é inevitável (a não ser que se morra), conforme expressou um dos entrevistados: "Todos nós, cada dia, tomamos uma dose de velhice" (Idoso 2).

Relataram ainda que, para uma boa velhice é preciso ter saúde e fazer alguma atividade. A satisfação que a maioria relatou ter, na vivência desta fase, está ligada à possibilidade de fazer coisas que não podiam fazer antes, por causa de outras prioridades, como, por exemplo, viajar. Também se mostraram gratos a Deus pela vida e pelos desafios superados. Se mostraram preocupados com a família, no sentido de se sentirem responsáveis pelos seus familiares e não quererem dar trabalho a eles. A família também foi identificada como fonte de apoio e incentivo e a casa como um lugar seguro e onde querem viver. Em duas entrevistas, as idosas relataram possibilidade de irem para o que chamaram de asilo e abrigo, por conta própria, caso venham a se encontrar em situação de não conseguirem mais cuidar de si mesmas. Um entrevistado se referiu ao asilo, como um lugar que ele não quer ir e, se for, ficará chateado.

A boa velhice, como deixaram a entender, não acontece naturalmente e demanda iniciativas, por parte dos idosos, como ter uma boa alimentação, seguir recomendações médicas, fazer coisas que trazem satisfação e gostar de si mesmos. Trata-se, então, de um desafio, uma vez que, além da iniciativa pessoal, deve-se considerar a realidade socioeconômica, ambiental e relacional do indivíduo.

A respeito desta realidade desafiadora, Ferreira et al. (2012) asseguram que, mesmo diante das perdas durante o processo de envelhecimento, deve-se estimular o envelhecer de maneira ativa, pois ele é sinônimo de vida plena e com qualidade. $O$ envelhecimento ativo corresponde ao equilíbrio biopsicossocial de um indivíduo, que é capaz de desenvolver suas potencialidades e que está inserido, integralmente, em um contexto social. Para estas autoras, é muito importante o apoio da política, da família, da sociedade, da rede de amigos e dos grupos de interesses comuns, na luta contra a discriminação e o preconceito que gira em torno do envelhecimento.

Foi possível verificar também um sistema de crenças e valores arraigados nos discursos dos entrevistados, relacionados a religiosidade, família, ajuda ao próximo e intergeracionalidade, indicando que a representação social destes idosos sobre o envelhecimento e velhice se remete à necessidade de ser responsável por suas decisões, como protagonista de sua história, e, tendo em vista que não se pode parar o tempo, devese viver com intensidade, saúde, buscando ter alguma atividade, procurando ensinar e aprender, mesmo com tantos desafios, principalmente em uma sociedade em que ainda se percebe a existência de estereótipos e estigmas direcionados às pessoas na faixa etária em que se encontram.

\section{Classificação Hierárquica Descendente}

Para entender, com maior profundidade, o significado do envelhecimento e da velhice para os idosos, realizou-se a Classificação Hierárquica Descendente (CHD). O resultado mostrou um corpus constituído por oito entrevistas, separadas em setenta e cinco segmentos de

Temporalis, Brasília (DF), ano 18, n. 35, jan./jun. 2018. 
texto (ST), com aproveitamento de cinquenta e seis ST's (74,67\%). Emergiram 2.593 ocorrências (palavras, formas ou vocábulos), sendo 500 palavras distintas e 254 com uma única ocorrência. O conteúdo analisado foi categorizado em quatro classes: Classe 1, com quinze ST (26,8\%), Classe 2, com dezessete ST (30,4\%), Classe 3, com treze ST (23,2\%) e Classe 4, com onze ST (19,6\%).

As classes se encontram divididas em três ramificações ( $A, B$ e C), conforme a Figura 2. A associação da palavra com a classe foi evidenciada pelo Qui Quadrado $\left(X^{2}\right)$, que, de acordo com Dancey e Reidy (2006), testa uma hipótese nula de que determinada palavra não tem relação com uma determinada classe. Se o p-valor for maior que o nível de significância $(\alpha=0,05)$, aceita-se tal hipótese. Neste sentido, conforme Lins ([2017]), considerou-se somente o $X^{2}>3,80$ e $p$-valor $<0,05$, eliminando-se as demais palavras.

Figura 2: Dendograma representativo das repartições em classes, porcentagem, frequência das palavras e qui-quadrado das representações sociais dos idosos sobre envelhecimento e velhice

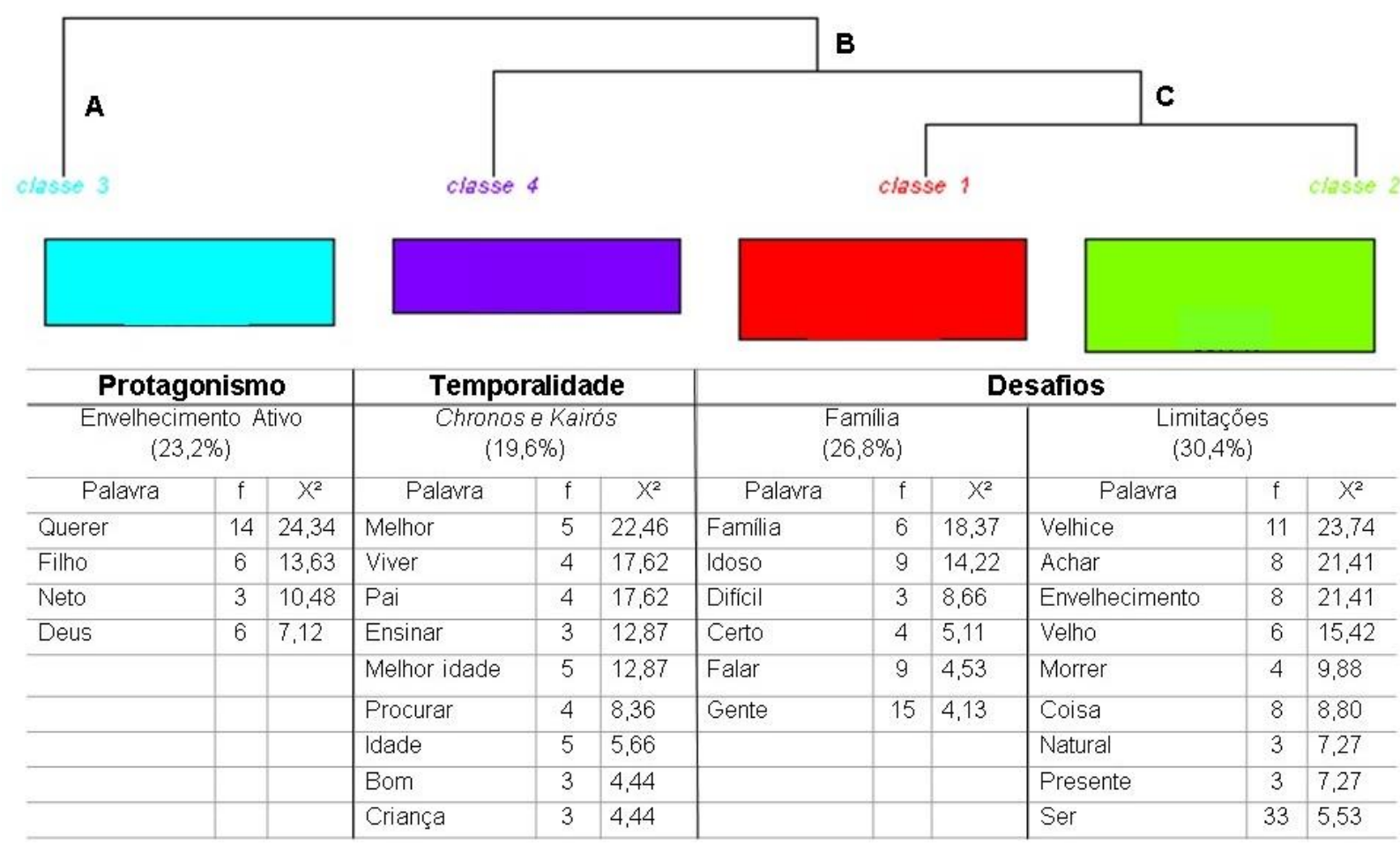

Fonte: Dados de pesquisa.

A partir do corpus colorido, gerado pelo Iramuteq, foi possível nomear as ramificações e as classes, com base nas respostas que foram associadas a cada uma delas. A apresentação dos resultados está conforme a ordem e a divisão que emergiu após o processamento das entrevistas, buscando respeitar a classificação hierárquica descendente realizada com o apoio do software.

A ramificação A, denominada Protagonismo, que explica $23,2 \%$ do total do corpus, é composta pela Classe 3, intitulada Envelhecimento Ativo, e emerge como foco principal para iniciar a apresentação das respostas sobre significado do envelhecimento e velhice dos idosos entrevistados, que compreende ter gratidão pela vida, em face à capacidade de

Temporalis, Brasília (DF), ano 18, n. 35, jan./jun. 2018. 
assumir o controle e tomar decisões, envolvendo a valorização da autonomia e da independência. Alguns dos seguimentos de textos destacados, permitem identificar essa realidade:

\section{[...] graças a Deus Deus me deu esse dom de ser um cidadão ativo (Idoso 1). \\ [...] a velhice é aquilo que você não pode parar. Você tem que dar seguimento à sua vida até Deus permitir (Idoso 2).}

O sentimento de gratidão, ao ser expressado durante as entrevistas, veio acompanhado de sorrisos, indicando satisfação pela vida. Tal sentimento vem ao encontro do que Silva (2006) considera como projetos de velhice, pois são feitos de gozo, afetividade, relações intergeracionais solidárias, presença da família, numa convicção e esperança de vida autônoma e independente, até morrer ou muito próximo disso acontecer.

Ao determinarem o que querem e podem fazer, os idosos demonstraram que o envelhecimento ativo é capaz de lhes proporcionar autonomia e controle sobre suas vontades, até mesmo no momento de reconhecer que precisam de ajuda. Tal consideração foi observada nas seguintes declarações:

[...] em agosto eu faço setenta e nove, quer dizer, eu trabalho, mês que vem eu vou pra Europa sozinha porque eu tenho uma filha que mora lá. Então por quê? Porque eu tenho atividade (Idosa 3).

[...] eu vou, eu quero ir, eu falo isso na minha casa e com todas as pessoas. Eu uso um termo até engraçado 'eu quero ir para um abrigo com as minhas pernas', não quero que ninguém me leve (Idosa 8).

A autonomia, conforme explica Fonseca e Siqueira (2015), é condição para que o indivíduo tenha o poder de determinar a própria lei e a capacidade de realizar. Para Souza, Boechat e Cabral (2015), a apropriação das vivências remete à responsabilidade individual e social, de modo que se pode configurar ativamente os seus dias de velhice. A respeito do poder de decisão sobre onde viver, Silva (2006), em sua tese, chama a atenção para o fato de que, embora seja claro o desejo de continuar a viver no próprio domicílio até o fim, admite-se a institucionalização, vista, de forma generalizada, como um mal menor, em casos de perda de autonomia e consequente dependência, a fim de não sobrecarregar a geração descendente.

Partindo dessa percepção de protagonismo, envolvendo gratidão e envelhecimento ativo, segue-se a segunda ramificação (B), denominada Temporalidade (19,6\% do total do corpus), que contém as percepções correspondentes à Classe 4 (Chronos e Kairós), cuja análise permite inferir que se refere ao fato de que a idade cronológica não impede de viver e agir de maneira saudável e de aproveitar o tempo presente, para fazer coisas que não foi possível fazer antes. Indica um desejo de continuidade, de viver bem e por mais tempo, como observado nestes trechos:

[...] agora, tem a maneira certa de agir pra que a pessoa tenha uma vida saudável, possa ajudar mais a sociedade, possa viver mais. E aí, isso é que nós, é o que eu penso que nós devemos procurar, devemos buscar no nosso dia a dia (Idoso 1).

Temporalis, Brasília (DF), ano 18, n. 35, jan./jun. 2018. 


\section{ewentecemerrove vatures temporolis}

[...] pra mim é tudo de bom porque hoje, com a idade que eu tenho, eu vivo muito melhor do que com a idade anterior (Idosa 5).

[...] sempre pensar que cheguei e vou fazer muito mais ainda né (Idosa 7).

De acordo com Oliveira, Guimarães e Rodrigues Jr (2015), não se define a velhice por simples cronologia, mas deve-se considerar as condições físicas, funcionais, mentais e de saúde do indivíduo.

Pedroni (2014) esclarece sobre a relação antagônica entre os mitos gregos de Chronos e Kairós, que serve simultaneamente de imã e catalisador para a pergunta sobre os limites dos tempos particular e partilhado. Por definição, Chronos é o tempo subordinado ao relógio e do qual não consegue fugir; Kairós é a qualidade do tempo vivido, um tempo oportuno, que faz um acontecimento ser especial, memorável, não em seus números, mas em sua significância. Ambos não se anulam e se fazem presença contínua no modo de habitar o mundo: "[...] um momento único e oportuno (Kairós) localizado em nossa rotina massificante (Chronos). A ressignificação do tempo observado é absorvida pela eternidade em pequenos pontos atemporais" (PEDRONI, 2014, p. 246).

Chama-se a atenção para o fato de que somente um entrevistado (Idoso 4) considerou a idade como fator limitante, em função das dificuldades pelas quais relatou estar passando. Ele contou da seguinte forma: “[...] minha preocupação é mais só isso mesmo: a gente não ter aquele equilíbrio que a gente tinha antes dos sessenta. É muito melhor antes” (Idoso 4).

Embora este idoso apresente características de um envelhecimento ativo, ao exercer sua cidadania e, até mesmo, participar de outros grupos, ligados à sua religiosidade, ele se mostrou insatisfeito com a passagem do tempo, considerando que ser velho the trouxe perdas, principalmente na saúde, além de considerar que os jovens o veem com ar de deboche, como alguém ultrapassado. Embora não precise de auxílio para realizar qualquer atividade, relatou que precisa de auxílio financeiro para pagar um médico particular. Tal descontentamento também foi percebido no trabalho de Tavares et al. (2012), ao analisarem a visão do idoso no que diz respeito a envelhecer, adoecer e tornar-se dependente. Segundo eles, depender de auxílio de outras pessoas gera sentimento de impotência e inutilidade para o idoso, podendo acarretar descontrole emocional, que tende a se agravar com a presença de conflitos familiares.

Adentra-se então em uma terceira ramificação (C), que, após análise, recebeu o nome de Desafios, sendo possível identificar a percepção do envelhecimento e velhice em duas classes. A Classe 1 (Família) e a Classe 2 (Limitações), com 26,8\% e 30,4\%, de explicação do total do corpus, respectivamente. Essa ramificação contempla representações que consideram a relação entre a família e o idoso e as percepções individuais mais específicas sobre envelhecer, ser velho e ser idoso em um contexto de limitações, com possíveis perdas e isolamento. É do Idoso 4 a seguinte declaração:

[...] e a gente se sente assim um pouco isolado. Eu me sinto isolado pela própria família. Me sinto isolado. A gente já não tem mais aquela habilidade de sempre, já não produz muito pra ajudar alguma coisa dentro de casa.

Temporalis, Brasília (DF), ano 18, n. 35, jan./jun. 2018. 


\section{tempordlis}

LUIZ, KARINE K. I.; LORETO, MARIA DAS D. S. DE; MAFRA, SIMONE C. T.; FERREIRA, MARCO A. M.

Foi possível identificar, a partir de sua fala, que ele está descontente com sua família e não se sente acolhido. Falou que não gostaria de ir para um asilo, justificando ainda mais o motivo de tanta preocupação que apresentou, quando lhe foi perguntado sobre o que significava, para ele, o envelhecimento e a velhice. Fazendo um contraste com essa realidade, Frumi e Celich (2006) destacam que, quando o idoso se sente respeitado e tem seu saber e sua história de vida valorizados, ele encontra um significado para a sua existência. Atitudes de consideração, respeito e amor acolhem o idoso e promovem um sentido no envelhecer.

Outra representação sobre esta etapa da vida diz respeito à maneira como se reage diante das limitações que vão surgindo, deixando transparecer que o idoso também tem responsabilidade sobre sua qualidade de vida:

[...] então eu considero que a velhice é uma coisa, é um acontecimento na vida do ser humano, que nem todos vão passar por ela, não vai sair, eu considero que nós devemos buscar uma vida saudável [...] então é o que eu penso da velhice. Acho que, como todos vão ficar, então vamos ficar, mas vamos ficar velho, ficar um velho autêntico, um velho saudável, um velho, como se diz, não preguiçoso. Gostar da gente pra que a gente possa fazer uma comunidade mais feliz (Idoso 1).

Neste sentido, Souza, Boechat e Cabral (2015) consideram que, dependendo da compreensão que se tem do envelhecimento, ele pode representar um problema ou então uma oportunidade para viver novidades, compartilhar vivências, aprender sempre e desenvolver projetos, fazendo menção à responsabilidade que a pessoa tem para com sua vida e com a vida dos demais familiares.

Os desafios da vivência desta fase da vida também se manifestam no próprio entendimento do significado do envelhecimento e da velhice, conforme se percebe a representação social sobre estes termos. Notou-se uma preocupação, por parte de alguns, em não se identificar com a palavra velho, conforme foi exposto pela Idosa 3, logo no início da entrevista e também pela Idosa 5, ao buscar diferenciar o envelhecimento da velhice:

[...] primeiro nós vamos destacar o quê que é o envelhecimento e o quê que é a velhice porque há uma diferença entre o velho e o idoso. $O$ velho é aquele que fica em casa deitado [...] e o idoso não o idoso é aquela pessoa que tem atividade mesmo que aposentado fazendo trabalho voluntário ou caminha ou vai pra praça jogar baralho com os amigos, jogar dama. Então ele pouco para em casa, porque ele anda (Idosa 3).

[...] se eu reclamar é um pecado. Eu acho que depende muito das pessoas porque, se a pessoa achar que ele está velho, ele acomoda. Então eu acho que a idade é uma coisa que a gente tem mas deixa de lado e vamos tocando a vida, vamos levando a vida (Idosa 5).

Este posicionamento frente ao significado de velho e idoso foi identificado na pesquisa de Rozendo (2010), ao notar que os idosos não se enxergam como velhos, no sentido conotativo do termo, não sendo raro se deparar com pessoas bastante envelhecidas se posicionando a léguas de distância da velhice. Chegam, segundo este autor, a lançar um tom de caridade ao se dirigirem aos chamados velhos e que tal comportamento é bastante 
comum dentre dirigentes de instituições asilares, já idosos, mas que não se colocam no lugar de velhos.

É desafiador também constatar que o tempo está passando, descortina-se novas paisagens, como sugere Abreu (2017), sendo necessário aceitar as perdas decorrentes. Verificou-se, no entanto, uma disposição para continuar vivendo, conforme o relato dos entrevistados, exemplificados assim:

[...] então é difícil a gente, às vezes, aceitar a ideia que tá ficando idosa né? Mas eu, no meu pensamento, eu penso que é uma glória, uma virtude, um bem que Deus passa pra gente, isso (Idosa 7).

[...] envelhecimento pra mim é uma coisa natural né. Tudo nasce, cresce, envelhece e morre. Então é uma coisa natural. Só não vejo a velhice limitada (Idosa 6).

Embora seja possível pensar que as limitações que surgem ao longo do tempo possam trazer dificuldades, Peixoto (2004), ao falar sobre processos diferenciais do envelhecimento, ressalta que o avançar da idade não é sinônimo de decadência e isolamento, para muitos, tendo em vista que não se deixam influenciar pela diminuição das possibilidades de participação ou integração e vivem um eterno processo de adaptação e de reconversão.

\section{CONSIDERAÇÕES FINAIS}

As representações sociais de idosos, a partir da análise de conteúdo e lexical, realizada pelo software Iramuteq, permitiram compreender o significado do envelhecimento e da velhice junto aos idosos, se mostrou muito favorável, pois, além da análise lexical, que considera a palavra como unidade, o software também oferece a contextualização dos textos e a formação das classes explicativas e seus respectivos pesos. No que concerne às palavras, tiveram maior frequência, na explicação: Vida, considerando o envelhecer como um processo natural da vida humana; Saúde, como elemento determinante de uma vida ativa e saudável. É importante destacar que o significado do envelhecimento e da velhice dado pelos idosos entrevistados tem relação direta com o seu contexto e experiência de vida e se destacou por aspectos ligados, por um lado, ao protagonismo e vida ativa, mesmo diante da temporalidade; mas, por outro lado, às limitações decorrentes do envelhecimento, que levam aos desafios do dia-a-dia, onde a família tem papel de destaque.

Os dados preenchidos nas questões do perfil da amostra se mostraram úteis para a compreensão das respostas, pois, a partir das características pessoais apresentadas, foi possível entender o significado atribuído ao envelhecimento e velhice, influenciado pela atuação no Conselho Municipal do Idoso de sua cidade, considerando a autonomia presente nos papéis desempenhados pelos respectivos idosos entrevistados.

Apesar da limitação da amostra de idosos, derivado da acessibilidade dos possíveis informantes e existência de conselhos atuantes, acredita-se que o número de idosos entrevistados foi suficiente para atender ao objetivo proposto, gerando informações

Temporalis, Brasília (DF), ano 18, n. 35, jan./jun. 2018. 
significativas a respeito da representação social destes idosos sobre o envelhecimento e a velhice.

\section{REFERÊNCIAS}

ABREU, Maria Celia de. Velhice: uma nova paisagem. São Paulo: Ágora, 2017.

ALVES, Eustáquio Diniz. Transição Demográfica, Transição da Estrutura Etária e Envelhecimento. Revista Portal de Divulgação, ano 4, n. 40, p. 8-15, 2014.

AMARAL, Shirlena Campos de Souza; GUIMARÃES, Décio Nascimento; LIMA, Náthani Siqueira. In: MANHÃES, Fernanda Castro; ISTOE, Rosalee Santos Crespo; SOUZA, Carlos Henrique Medeiros de (Orgs.). Envelhecimento em foco: abordagens interdisciplinares II. Campos dos Goytacazes: Brasil Multicultural, 2015.

BARROS, Myriam Moraes Lins de. Velhice na Contemporaneidade. In: PEIXOTO, Clarice Ehlers (Org.). Família e Envelhecimento. Rio de Janeiro: Fundação Getúlio Vargas, 2004.

BREDEMEIER, Sonia Mercedes L. O Espaço Público e o Idoso: possibilidades através de um Conselho Municipal. Textos \& Contextos, Porto Alegre, v. 1, n. 1, p. 1-8, 2002.

CAMARGO, Brigido Vizeu. et al. Representações sociais do envelhecimento entre diferentes gerações no Brasil e na Itália. Psicologia em Pesquisa, Juiz de Fora, v. 8, n. 2, p. 179-188, 2014.

COELHO, Ruth dos Martins. Cidadania na velhice: estudo sobre as mulheres do grupo de convivência do CIAPREVI-CE. 2009. 243 f. Dissertação (Mestrado em Planejamento e Políticas Públicas)-Programa de Pós-Gradução da Universidade Estadual do Ceará, Fortaleza, 2009.

DANCEY, Christine P.; REIDY, John. Estatística sem matemática: para psicologia usando SPSS para Windows. Porto Alegre: Artmed, 2006.

DOLL, Johannes. Bem-estar na velhice: mitos, verdades e discursos, ou a gerontologia na pós-modernidade. Revista Brasileira de Ciências do Envelhecimento Humano, Passo Fundo, v. 3, n. 1, p. 9-21, 2006.

FERNANDES, Janaína da Silva Gonçalves; MONTIEL, José Maria; ANDRADE, Márcia Siqueira de; BARTHOLOMEU, Daniel; CECATO, Juliana Francisa; MARTINELLI, José Eduardo. Análise discursiva das representações sociais de idosos sobre suas trajetórias de vida. Estudos Interdisciplinares sobre o Envelhecimento, v. 20, n. 3, p.903-920, 2015.

FERREIRA, Olívia Galvão Lucena; MACIEL, Silvana Carneiro; COSTA, Sônia Gusmão; SILVA, Antonia Oliveira; MOREIRA, Maria Adelaide Silva Paredes. Envelhecimento ativo e sua relação com a independência funcional. Texto Contexto Enferm., Florianopólis, v. 21, n. 3, p. 513-8, 2012. 
FIGUEIREDO, Maria Henriqueta de Jesus Silva; MARTINS, Maria Manuela Ferreira Pereira da Silva; SILVA, Luzia Wilma Santana da; OLIVEIRA, Palmira da Conceição Martins de. Ciclo vital da família e envelhecimento: contextos e desafios. Kairós Gerontologia, v. 14, p. 1122, 2011.

FONSECA, Rita de Cássia Andrade da; SIQUEIRA, Patrícia Terra. Psicomotricidade: uma proposta de movimento para um envelhecer saudável e autônomo. In: MANHÃES, Fernanda Castro; ISTOE, Rosalee Santos Crespo; SOUZA, Carlos Henrique Medeiros de (Orgs.). Envelhecimento em foco: abordagens interdisciplinares II. Campos dos Goytacazes: Brasil Multicultural, 2015.

FRUMI, Cailene; CELICH, Kátia Lilian Sedrez. O olhar do idoso frente ao envelhecimento e à morte. Revista Brasileira de Ciências do Envelhecimento Humano, Passo Fundo, v. 3, n. 2, p. 92-100, 2006.

GUERRA, Ana Carolina Lima Cavaletti; CALDAS, Célia Pereira. Dificuldades e recompensas no processo de envelhecimento: a percepção do sujeito idoso. Ciência \& Saúde Coletiva, v. 15, n. 6, p. 2931-2940, 2010.

GOMES, Denise da Silva; ISTOE, Rosalee Santos Crespo. Universidades Abertas e Envelhecimento Humano: uma revisão sobre marcos legais, cidadania e educação do idoso. In: MANHÃES, Fernanda Castro; ISTOE, Rosalee Santos Crespo; SOUZA, Carlos Henrique Medeiros de (Orgs). Envelhecimento em foco: abordagens interdisciplinares II. Campos dos Goytacazes: Brasil Multicultural, 2015.

GOMES, Denise da Silva; MANHÃES, Fernanda Castro; ISTOE, Rosalee Santos Crespo. Envelhecimento e Imagem Corporal: experiência em projeto para a terceira idade. In: MANHÃES, Fernanda Castro; ISTOE, Rosalee Santos Crespo; SOUZA, Carlos Henrique Medeiros de (Orgs.). Envelhecimento em foco: abordagens interdisciplinares II. Campos dos Goytacazes: Brasil Multicultural, 2015.

LINS, Cynthia Freitas de Melo. Apostila de Iramuteq. Fortaleza: Universidade de Fortaleza, Programa de Pós-Graduação em Psicologia, [2017]. (Material didático).

OLIVEIRA, André Luiz Gomes de; GUIMARÃES, Tatiane Carvalho Peçanha; RODRIGUES JÚNIOR, João Batista. Fatores Biopsicossociais e a Aposentadoria frente ao Envelhecimento. In: MANHÃES, Fernanda Castro; ISTOE, Rosalee Santos Crespo; SOUZA, Carlos Henrique Medeiros de (Orgs). Envelhecimento em foco: abordagens interdisciplinares II. Campos dos Goytacazes: Brasil Multicultural, 2015.

OSTERNE, Maria do Socorro Ferreira. Violência nas Relações de Gênero e Cidadania Feminina. Fortaleza: EdUece, 2008.

PEDRONI, Fabiana. Chronos e Kairós: determinações poéticas para o tempo vivido. Revista do Colóquio de Arte e Pesquisa do PPGA-UFES, Vitória, v. 3, n. 6, p. 245-254, 2014. 
PEIXOTO, Clarice Ehlers. Processos Diferenciais de Envelhecimento. In: PEIXOTO, Clarice Ehlers (Org.). Família e envelhecimento. Rio de Janeiro: Fundação Getúlio Vargas, 2004.

PESSIN, Giséle; ISTOE, Rosalee Santos Crespo; MANHÃES, Fernanda Castro. A sexualidade e o Envelhecimento na Contemporaneidade: reflexões sobre uma história em construção. In: MANHÃES, Fernanda Castro; ISTOE, Rosalee Santos Crespo; SOUZA, Carlos Henrique Medeiros de (Orgs.). Envelhecimento em foco: abordagens interdisciplinares II. Campos dos Goytacazes: Brasil Multicultural, 2015.

ROZENDO, Adriano da Silva. Construção social do envelhecimento e experiências da velhice. 2010. 106 f. Dissertação (Mestrado em Psicologia)-Programa de Pós-Graduação em Psicologia da Universidade Estadual Paulista, Assis, 2010.

SILVA, Camille Auattda; CARMO, Gerson Tavares. Revisão Bibliográficas sobre Universidades Abertas à Terceira Idade. In: MANHÃES, Fernanda Castro; ISTOE, Rosalee Santos Crespo; SOUZA, Carlos Henrique Medeiros de (Orgs). Envelhecimento em foco: abordagens interdisciplinares II. Campos dos Goytacazes: Brasil Multicultural, 2015.

SILVA, Jean Paulo; BOUSFIELD, Andréa Barbará da Silva; CARDOSO, Luiza Herzmann. A hipertensão arterial na mídia impressa: análise da revista Veja. Psicologia e Saber Social, Rio de Janeiro, v. 2, n. 2, p. 191-203, 2013.

SILVA, Maria Ester Vaz da. "Se fosse tudo bem, a velhice era boa de enfrentar!": racionalidades leigas sobre envelhecimento e velhice. 2006. 227 f. Tese (Doutorado em Sociologia)-Universidade Aberta, Lisboa, 2006.

SOUZA, Carlos Henrique Medeiros de; BOECHAT, leda Tinoco; CABRAL, Hildeliza Lacerda Tinoco Boechat. Sob as "Réstias de Sol" Fluminenses: tecnologia e publicação literária no "estágio tardio da vida". In: MANHÃES, Fernanda Castro; ISTOE, Rosalee Santos Crespo; SOUZA, Carlos Henrique Medeiros de (Orgs.). Envelhecimento em foco: abordagens interdisciplinares II. Campos dos Goytacazes: Brasil Multicultural, 2015.

TAVARES, Keila Okuda; SCALCO, Janaina Cristina; VIEIRA, Lizyana; SILVA, Joseane Rodrigues da; BASTOS, Carmen Célia Correia Barradas. Envelhecer, adoecer e tornar-se dependente: a visão do idoso. Kairós Gerontologia. Revista da Faculdade de Ciências Humanas e Saúde, São Paulo, v. 15, n. 2, p. 105-118, 2012. 